
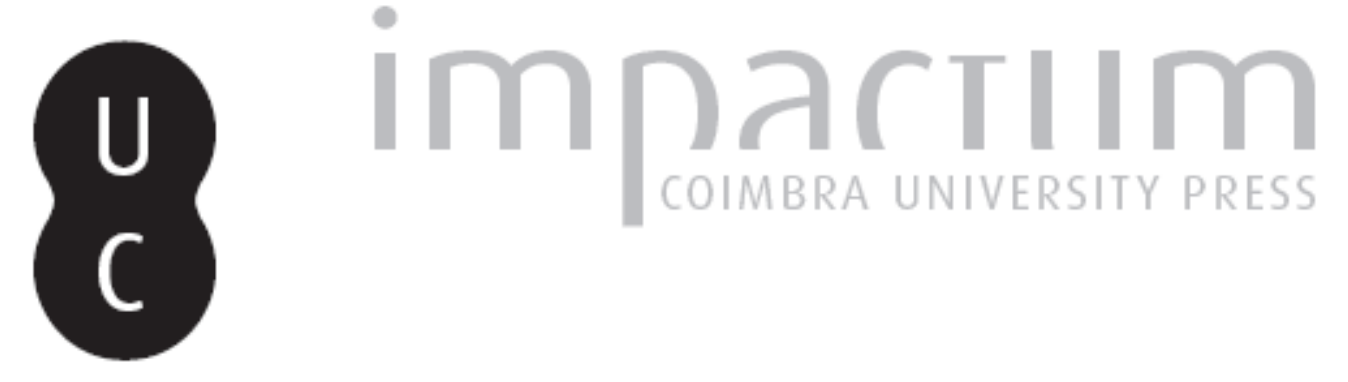

\title{
Um olhar sobre a revista Cadmo: história e estatística
}

Autor(es): $\quad$ Almeida, Isabel Castanhito de

Publicado por: Centro de História da Universidade de Lisboa

URL persistente:

URI:http://hdl.handle.net/10316.2/23622

DOI:

DOI:http://dx.doi.org/10.14195/0871-9527_21_12

Accessed : $\quad$ 26-Apr-2023 13:30:40

A navegação consulta e descarregamento dos títulos inseridos nas Bibliotecas Digitais UC Digitalis, UC Pombalina e UC Impactum, pressupõem a aceitação plena e sem reservas dos Termos e Condições de Uso destas Bibliotecas Digitais, disponíveis em https://digitalis.uc.pt/pt-pt/termos.

Conforme exposto nos referidos Termos e Condições de Uso, o descarregamento de títulos de acesso restrito requer uma licença válida de autorização devendo o utilizador aceder ao(s) documento(s) a partir de um endereço de IP da instituição detentora da supramencionada licença.

Ao utilizador é apenas permitido o descarregamento para uso pessoal, pelo que o emprego do(s) título(s) descarregado(s) para outro fim, designadamente comercial, carece de autorização do respetivo autor ou editor da obra.

Na medida em que todas as obras da UC Digitalis se encontram protegidas pelo Código do Direito de Autor e Direitos Conexos e demais legislação aplicável, toda a cópia, parcial ou total, deste documento, nos casos em que é legalmente admitida, deverá conter ou fazer-se acompanhar por este aviso.

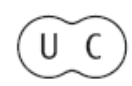



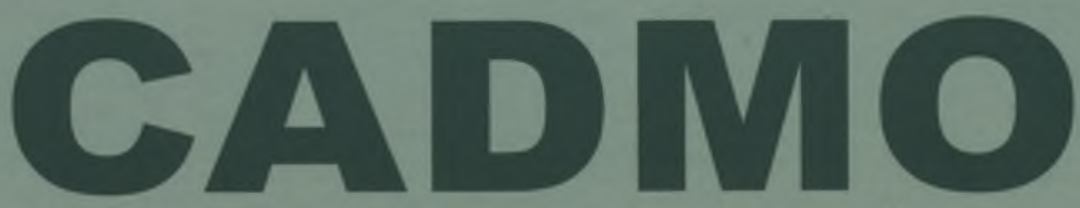

Revista de História Antiga

\author{
Centro de História \\ da Universidade de Lisboa
}

\title{
21
}

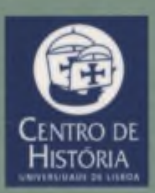

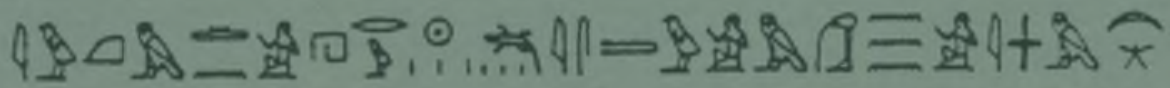

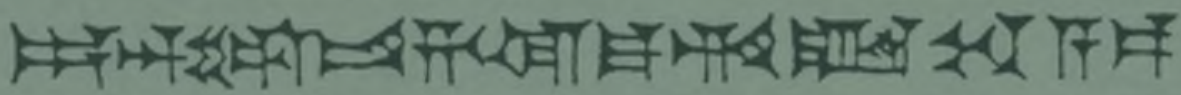

MHNIN AEI $\Delta \mathrm{E} \Theta \mathrm{EA}$ ПH$\Lambda \mathrm{HIA} \triangle \mathrm{E} \Omega$ 


\section{UM OLHAR SOBRE A REVISTA CADMO: HISTÓRIA E ESTATÍSTICA}

ISABEL CASTANHITO DE ALMEIDA

Universidade de Lisboa

\section{Introdução}

$\mathrm{Na}$ intenção de assinalar os vinte anos de publicação da revista Cadmo, nasceu a ideia de realizar um trabalho de investigação esta revista iniciada pelo Instituto Oriental da Faculdade de Letras da Universidade de Lisboa e agora editada pelo Centro de História da mesma instituição. O primeiro capítulo do trabalho consiste numa evocação da história da revista, abordando-se a sua origem e explicação do título, o seu objecto de estudo, os membros da direcção, redacção e conselho científico, a organização da revista, qual o seu público-alvo, a sua periodicidade, tiragem e preço, entre outras informações de relevo. O segundo capítulo consiste na exposição sintética do percurso académico e profissional dos directores e dos redactores permanentes da revista Cadmo. De seguida, faremos o inventário de todos os estudos da revista, inseridos nas suas grandes áreas de investigação: Egipto Faraónico, Civilizações da Mesopotâmia (Sumérios, Acádios, Babilónios, Assírios), Síria-Palestina (Hebreus, Fenícios e Cananeus), Grécia e Roma, Misto (artigos que reúnem em si mais do que uma categoria) e Diversos (artigos sobre outros temas). A partir daí, elaboraremos dois gráficos que mostram os dados estatísticos por número de artigos e os dados estatísticos por percentagem, que nos dão a percepção da incidência dos estudos nas diversas categorias em análise. No final, faremos um balanço dos vinte anos da revista Cadmo, 
relevando o seu contributo na divulgação de estudos científicos no âmbito da História Antiga.

A elaboração do presente trabalho teve como bibliografia consultada todos os números da revista Cadmo, desde o número 1 (1991) ao número 20 (2010), bem como algumas obras dos directores e redactores da revista, com vista a elaborar os seus percursos académicos e profissionais.

\section{História da revista Cadmo}

A revista Cadmo nasceu da vontade do Instituto Oriental de criar uma revista que seria um espaço de divulgação de estudos no âmbito de História Antiga, nomeadamente nas áreas da Orientalística antiga, como a egiptologia, assiriologia, hititologia e hebraística. Assim, esta revista promoveria a publicação de trabalhos de especialistas nacionais e estrangeiros, em português ou em outras línguas.

De facto, com espaço próprio desde 1990, o Instituto Oriental da Faculdade de Letras da Universidade de Lisboa (fundado em 1986) conseguiu incrementar as suas actividades, nas quais se inclui a publicação do primeiro número da revista Cadmo que saiu em 1991. Tinha como director José Nunes Carreira, na altura também director do Instituto Oriental, e faziam parte do corpo redactorial José Augusto Ramos, António Ramos dos Santos e Luís Manuel de Araújo, docentes da área de História Pré-Clássica na referida Faculdade.

Além disso, a revista contava com colaboradores permanentes de vários pontos do mundo: Emanuel Bouzon (Rio de Janeiro), Francolino Gonçalves (Jerusalém), Gustav Adolf Lehmann (Colónia e posteriormente de Göttingen), Manuel Augusto Rodrigues (Coimbra), Josep Padró (Barcelona) e Julio Trebolle (Madrid), e, a partir da Cadmo 4/5 (1994-1995), Geraldo Coelho Dias (Porto). Em 2004, José Nunes de Carreira jubilou-se, pelo que a partir da Cadmo 15 (2005), o novo director passou a ser José Augusto Ramos.

O título desta revista evoca o herói tírio lendário, fundador da cidade grega de Tebas e introdutor do alfabeto fenício na Grécia. Com efeito, a escrita foi um dos saberes e artes que chegaram à Grécia através de Cadmo e dos fenícios que o acompanhavam. Se até ao número $15 \mathrm{da}$ revista se explorava o Próximo Oriente - o ponto de partida do herói Cadmo -, a partir de então, investiga-se também o Ocidente, nomeadamente a Grécia e Roma - o ponto de chegada de Cadmo. Isto tornou-se possível 
graças à participação dos historiadores de História da Antiguidade Clássica do Departamento de História da Faculdade de Letras de Lisboa, bem como de outros investigadores de outras universidades que se dedicam ao mundo clássico. Se o objecto de estudo se alargou, também a equipa científica aumentou e sofreu alterações. Neste sentido, a partir da Cadmo 16 (2006), fazem parte do secretariado o egiptólogo Luís Manuel de Araújo e o classicista Nuno Simões Rodrigues.

O corpo redactorial manteve-se e alargou-se com a colaboração de Nuno Simões Rodrigues, Tatiana Kuznetsova-Resende e Amílcar Guerra. O conselho científico de colaboradores permanentes também sofreu algumas modificações e aumentou. Aos anteriores colaboradores Francolino Gonçalves (Jerusalém), Geraldo Coelho Dias (Porto), Josep Padró (Barcelona) e Julio Trebolle (Madrid), juntaram-se Eva Cantarella (Milão), Giulia Sissa (Los Angeles), John J. Collins (Yale), José Manuel Roldán Hervás (Madrid), José Ribeiro Ferreira (Coimbra), Juan Pablo Vita (Saragoça), Ken Dowden (Birmingham), Maria Cristina de Sousa Pimentel (Lisboa), Maria de Fátima Sousa e Silva (Coimbra), Marta Sordi (Milão), Mireille Hadas-Lebel (Paris) e, desde a Cadmo 18 (2008), Antonio Loprieno (Basileia). Entretanto Emanuel Bouzon (Rio de Janeiro) faleceu e Gustav Adolf Lehmann (Göttingen) e Manuel Augusto Rodrigues (Coimbra), já jubilados, deixaram de integrar o quadro técnico da revista.

Quanto à estrutura da revista, ela tem por vezes um editorial (Cadmo 1 e 4/5) e, no caso dos números 10 e 12, por constituirem a publicação de actas de colóquios (um deles a nível internacional), abrem com o discurso de abertura (Cadmo 10) e por uma nota introdutória (Cadmo 12). Seguem-se os estudos/artigos (o número é variável - entre 4 a 11 artigos por número) e a secção de "Notas e Comentários" e de "Recensões", presente em todos os números, menos os da publicação de actas, como se compreende. Alguns números contêm um capítulo intitulado "Crónica" $(1,2,3,4 / 5,14,15$ e 19) e "Vida do Instituto" (1, 2, 3, 4/5 e 6/7), onde se dão a conhecer resumos de teses, informações sobre os programas de mestrado na área de História Antiga, actividades levadas a cabo pelo Instituto Oriental e pelos seus docentes.

Sendo uma revista de periodicidade anual, há números duplos Cadmo 4/5 (1994-1995), 6/7 (1996-1997) e 8/9 (1998-1999), com uma tiragem de 1000 exemplares. O preço actual da revista, que vem estipulado na sua ficha técnica (p. 4), é 9.50 euros. A revista pode ser adquirida no Instituto Oriental e no Centro de História, existindo dois números (os números duplos 4/5 e 6/7 nas Edições Colibri, sendo ainda possivel encontrar números mais antigos em algumas livrarias e alfarrabistas. Se 
o público-alvo principal são os investigadores e estudantes universitários, ele alarga-se a todos os que estiverem interessados em conhecer estudos científicos na área de História Antiga.

Quanto ao financiamento da revista e parcerias/patrocinadores, a Cadmo contou com o apoio da Fundação Calouste Gulbenkian nos números 1 (1991), 10 (2000) e 12 (2002), com o patrocínio da Faculdade de Letras da Universidade de Lisboa e do Centro de História da Universidade de Lisboa nos números 6/7 (1996-1997), 8/9 (1998-1999) e 11 (2001) e desde 2006 (Cadmo 16) com o financiamento do Programa Operacional Ciência, Tecnologia, Inovação do Quadro Comunitário de Apoio III (inserido no âmbito da FCT - Fundação para a Ciência e a Tecnologia, que é possível graças a fundos estruturais da União Europeia). Para a concepção gráfica e impressão, a revista trabalhou com as Edições Cosmos para a Cadmo 1 (1991), 2 (1992) e 3 (1993), as Edições Colibri para a Cadmo 4/5 (1994-1995), 6/7 (1996-1997) e desde 1998-1999 (Cadmo 8/9) com a Gráfica de Coimbra.

\section{Os directores e os principais redactores da revista}

O primeiro director da revista, e também seu fundador, José Nunes Carreira, é hoje professor catedrático jubilado da Faculdade de Letras de Lisboa. Construiu o seu percurso académico em Leiria, Roma e Jerusalém, tendo realizado estágios de investigação em Heidelberg e Bochum. Foi docente na Universidade Católica Portuguesa em Lisboa (1974-1978), na Universidade dos Açores em Ponta Delgada (1978-1984) e na Faculdade de Letras da Universidade de Lisboa desde 1984, tendo-se jubilado em 2004. Fundador e director do Instituto Oriental até 2004, foi ainda director da revista Clio (Centro de História). Especialista em História das Civilizações Pré-Clássicas com investigação específica em Estudos Bíblicos (Hebraística), é autor de muitos artigos e entradas de dicionários, tendo publicado diversas monografias, tais como Mito, Mundo e Monoteísmo (1993), Filosofia Antes dos Gregos (1994), Historiografia Hitita (1999), Cantigas de Amor do Oriente Antigo (1999), Literaturas da Mesopotâmia (2002), Literatura do Egipto Antigo (2005), Mitos e Lendas Hititas (2009). É membro da Associação Portuguesa de Orientalismo.

Redactor e novo director do Instituto Oriental e da revista Cadmo desde 2005, José Augusto Ramos é especialista em história e cultura préclássica, história das religiões pré-clássicas, línguas semíticas (hebraico, aramaico, fenício, ugarítico, acádico, siríaco), bem como em línguas 
clássicas (latim e grego). Iniciou o seu percurso académico em Roma e em Toulouse e doutorou-se em História e Cultura Pré-Clássica na Universidade de Lisboa. Desempenhou vários cargos na Faculdade de Letras da Universidade de Lisboa e no Centro de História, onde é director. Autor de inúmeras obras e artigos, pode-se destacar Evangelho Segundo Tomé (1992), Bíblia Sagrada. Tradução em Português Corrente (1993) e Bíblia Sagrada (1. ${ }^{a}$ ed. 1998). É agora professor catedrático jubilado da Faculdade de Letras da Universidade de Lisboa, continuando como presidente da direcção da Associação Portuguesa de Orientalismo.

António Ramos dos Santos é redactor permanente da revista, sendo licenciado em História (1981) e doutorado em Letras na especialidade de História Pré-Clássica (1999) pela Universidade de Lisboa, onde é professor auxiliar do Departamento de História. Investigador do Centro de História e do Instituto Oriental desta Faculdade, é especialista em História Económica da Mesopotâmia. Para além de vários artigos na sua área de investigação, é autor das obras A Estrutura Sócio-administrativa dos Templos em Babilónia (1989), A Babilónia dos Caldeus: uma caracterização socioeconómica (2003) e co-autor das obras Mundo Antigo. Economia Rural (2003) e História comparada dos sistemas bancário e de crédito (2009). É membro da Associação Portuguesa de Orientalismo.

Luís Manuel de Araújo é secretário da Cadmo e um dos seus redactores permanentes. Professor auxiliar da Faculdade de Letras da Universidade de Lisboa, licenciou-se nesta mesma Faculdade em História, com estágio de pós-graduação em Egiptologia na Faculdade de Arqueologia da Universidade do Cairo (1984-1985) e doutorou-se em Letras na especialidade de História e Cultura Pré-Clássica pela Universidade de Lisboa, tendo feito a sua agregação em 2009. Tem participado em vários congressos de Egiptologia no estrangeiro, bem como em congressos, encontros, seminários, jornadas arqueológicas e em inúmeras conferências de divulgação em Portugal. É secretário da Associação Portuguesa de Orientalismo e da Associação Cultural de Amizade Portugal-Egipto e membro grão-louvado da Confraria Queirosiana. Como egiptólogo, foi assessor científico de várias exposições e comissário científico da exposição permanente de antiguidades egípcias do Museu Nacional de Arqueologia (1993) e da sua congénere da Universidade do Porto (2011), sendo de destacar a sua participação no Dicionário do Antigo Egipto (2001). Além de mais de cem artigos de temática egiptológica e queirosiana, é autor de várias obras, como Eça de Queirós e o Egipto Faraónico (1987), Antiguidades Egípcias (1993), Estudos sobre Erotismo no Antigo Egipto (1995), O Clero do Deus Amon no Antigo Egipto (1999), Imagens do Egipto Queirosiano (2002), 
Egipto: As Pirâmides do Império Antigo (2003), Estatuetas Funerárias Egípcias da XXI Dinastia (2003), Mitos e Lendas do Antigo Egipto (2005), Arte Egípcia. Colecção Calouste Gulbenkian (2006), Os Grandes Faraós do Antigo Egito (2011), A Coleção Egípcia da Universidade do Porto (2011), tendo sido co-autor de As Comunicações na Antiguidade (2006) e A Farmácia no Mundo Pré-Clássico e nas Culturas Tradicionais (2008).

Os classicistas Nuno Simões Rodrigues, Tatiana Kuznetsova-Resende e Amílcar Guerra integram o corpo redactorial da revista Cadmo desde 2006, redigindo artigos de temática clássica.

Nuno Simões Rodrigues é licenciado em História, mestre em História e Cultura Pré-Clássica e doutorado em Letras, na especialidade de História da Antiguidade Clássica, pela Universidade de Lisboa. É docente da área de História Antiga do Departamento de História da Faculdade de Letras da Universidade de Lisboa, e é investigador do Centro de História da Universidade de Lisboa e do Centro de Estudos Clássicos e Humanísticos da Universidade de Coimbra. É autor de diversos artigos e obras nos domínios da Cultura Grega, História Política e Social de Roma e Literatura Clássica, como O Rei Saul Segundo Flávio Josefo (2000), Traduções Portuguesas de Teócrito (2000), Mitos e Lendas da Roma Antiga (2005) e co-autor de Mundo Antigo. Economia Rural (2003) e As Comunicações na Antiguidade (2006). Também traduziu Memórias de Agripina (2000) e O Processo Nero de Pierre Grimal (2002).

Tatiana Kuznetsova-Resende é licenciada em História e Arqueologia pela Universidade Lomonossov de Moscovo, com equivalência à licenciatura portuguesa em História, e é doutorada em História Clássica pela Universidade de Lisboa. Investiga na área de Arqueologia e de História e Cultura Clássicas e é especialista em mosaística. É autora de várias publicações em Portugal e no estrangeiro, como O Culto Dionisíaco em Portugal (1988) e é co-autora de Mundo Antigo. Economia Rural (2003).

Amílcar Guerra é licenciado em Filologia Clássica, mestre em Literaturas Clássicas e doutorado em História Clássica pela Universidade de Lisboa. Participou em vários projectos de intervenção arqueológica em Portugal e em Itália. Lecciona no Departamento de História da Faculdade de Letras de Lisboa e é investigador do Centro de Arqueologia (UNIARQ), tendo trabalhado nas áreas da epigrafia, arqueologia e história antiga peninsulares. É autor de Plínio-o-Velho e a Lusitânia (1995) e co-autor de Viriato. Genealogia de um mito (1992), Mesas do Castelinho, Almodôvar. Uma fortificação rural islâmica do Baixo Alentejo (2001) e de Mundo Antigo. Economia Rural (2003). 


\section{Grandes áreas de investigação da revista - dados estatísticos}

Segue-se o inventário dos estudos de todos os números da Cadmo, inseridos nas grandes áreas de investigação da revista, com a enumeração feita de acordo com a paginação de cada número e não por ordem alfabética dos seus autores. A partir da inventariação feita, apresentam-se gráficos que mostram os dados estatísticos por número de artigos e os dados estatísticos em percentagem, dando-nos a percepção da incidência dos estudos nas diversas categorias em análise.

\section{1) Egipto Faraónico}

\section{Cadmo 1}

Luís Manuel de Araújo, "De Charuhen a Kadech: relações entre o Egipto do Império Novo e a Ásia», Cadmo, 1, Lisboa, 1991, pp. 119-143.

\section{Cadmo 2}

Josep Padró, “Précisions sur deux momies de l'ancienne collection Toda", Cadmo, 2, Lisboa, 1992, pp. 7-14.

José Nunes Carreira, "Sabedoria evangélica no Antigo Egipto", Cadmo, 2, Lisboa, 1992, pp. 61-75. Luís Manuel de Araújo, «Aspectos do roteiro queirosiano no Egipto: Eça de Queirós na mastaba de Ti», Cadmo, 2, Lisboa, 1992, pp. 101-116.

\section{Cadmo 3}

Luís Manuel de Araújo, "Cones funerários da colecção de antiguidades egípcias do Museu Nacional de Arqueologia", Cadmo, 3, Lisboa, 1993, pp. 49-60.

\section{Cadmo 4/5}

Luís Manuel de Araújo, "O núcleo egípcio da colecção Assis Ferreira", Cadmo, 4/5, Lisboa, 1994-1995, pp. 75-94.

\section{Cadmo 8/9}

Luís Manuel de Araújo, "O núcleo egípcio da colecção Miguel Barbosa", Cadmo, 8/9, Lisboa, 1998-1999, pp. 69-106.

\section{Cadmo 10}

José Nunes Carreira, "O Egipto e as origens do monoteísmo", Cadmo, 10, Lisboa, 2000, pp. 11-40. Antonio Loprieno, "Toward a geography of Egyptian literature", Cadmo, 10, Lisboa, 2000, pp. 41-56.

Luís Manuel de Araújo, “Egiptologia em Portugal», Cadmo, 10, Lisboa, 2000, pp. 57-94.

Maria João Machado, “Neit na ideologia régia do Egipto”, Cadmo, 10, Lisboa, 2000, pp. 95-110. 


\section{Cadmo 11}

Erik Hornung, "Time in the Egyptian Netherworld", Cadmo, 11, Lisboa, 2001, pp. 7-14.

José Nunes Carreira, "O Egípcio, a Viagem e o Outro", Cadmo, 11, Lisboa, 2001, pp. 15-31.

Luís Manuel de Araújo, “A colecção egípcia do Museu do Caramulo», Cadmo, 11, Lisboa, 2001, pp. 55-63.

\section{Cadmo 12}

Luís Manuel de Araújo, "Os primórdios da ciência egiptológica", Cadmo, 12, Lisboa, 2002, pp. 63-84.

José das Candeias Sales, "A arqueologia egípcia no século XIX: da "caça ao tesouro" à salvaguarda da herança faraónica", Cadmo, 12, Lisboa, 2002, pp. 85-112.

\section{Cadmo 13}

Josep Padró, "Le site d'Oxyrhinchos: rapport sur les travaux archéologiques menés depuis 1992", Cadmo, 13, Lisboa, 2003, pp. 9-25.

Luís Manuel de Araújo, "Tecidos coptas numa exposição do Museu Nacional de Arte Antiga", Cadmo, 13, Lisboa, 2003, pp. 79-96.

Esther Pons Mellado, "Los metales en el mundo de las transacciones comerciales internacionales entre Egipto y otros paises hasta el Imperio Nuevo", Cadmo, 13, Lisboa, 2003, pp. 111-127.

\section{Cadmo 14}

José Nunes Carreira, "A narrativa na literatura do Egipto Antigo", Cadmo, 14, Lisboa, 2004, pp. 9-30.

Luís Manuel de Araújo, "Seis novos objectos da colecção egípcia do Museu Nacional de Arqueologia", Cadmo, 14, Lisboa, 2004, pp. 53-60.

Maria Ana Valdez, "O Conto do Náufrago. Três personagens à procura de intérprete", Cadmo, 14, Lisboa, 2004, pp. 109-123.

Telo Ferreira Canhão, "O Conto do Camponês Eloquente na literatura do Antigo Egipto", Cadmo, 14, Lisboa, 2004, pp. 125-143.

Pedro Correia Marques, "Dois contributos complementares para a teologia da unidade de deus no Egipto: Erik Hornung e Jan Assmann», Cadmo, 14, Lisboa, 2004, pp. 175-188.

\section{Cadmo 15}

Luís Manuel de Araújo, "O sarcófago egípcio do Museu da Farmácia", Cadmo, 15, Lisboa, 2005, pp. 23-32.

Rogério Ferreira de Sousa, "Os amuletos do coração no antigo Egipto: tipologia e caracterização", Cadmo, 15, Lisboa, 2005, pp. 105-130.

Pedro de Abreu Malheiro, "A era dos Ramsés: apogeu da piedade pessoal», Cadmo, 15, Lisboa, 2005, pp. 131-162.

Telo Ferreira Canhão, "Datação e temática do Conto do Camponês Eloquente", Cadmo, 15, Lisboa, 2005, pp. 163-187. 
Esther Pons Mellado, "Los enanos orfevres en los talleres metalurgicos del antiguo Egipto", Cadmo, 15, Lisboa, 2005, pp. 189-200.

\section{Cadmo 16}

Telo Ferreira Canhão, "O Conto do Camponês Eloquente”, Cadmo, 16, Lisboa, 2006, pp. 11-54. Pedro de Abreu Malheiro, «A prática da guerra no antigo Egipto: organização do exército no Império Novo", Cadmo, 16, Lisboa, 2006, pp. 55-81.

Esther Pons Mellado, "Genios-guardianes y animales en el mundo de la metalurgia del antiguo Egipto", Cadmo, 16, Lisboa, 2006, pp. 83-100.

José das Candeias Sales, «As fórmulas protocolares egípcias ou formas e possibilidades do discurso de legitimação no antigo Egipto", Cadmo, 16, Lisboa, 2006, pp. 101-124.

Luís Manuel de Araújo, "Vasos de vísceras em colecções egípcias de Portugal», Cadmo, 16, Lisboa, 2006, pp. 125-138.

\section{Cadmo 17}

Telo Ferreira Canhão, “Khuenanupu, um camponês eloquente», Cadmo, 17, Lisboa, 2007, pp. 81-112.

Pedro de Abreu Malheiro, «A prática da guerra no Egipto do Império Novo (2. ${ }^{a}$ parte): Alguns elementos prosopográficos dos militares e o seu sistema social», Cadmo, 17, Lisboa, 2007, pp. 113-142.

\section{Cadmo 18}

Rogério Ferreira de Sousa, "O amuleto cordiforme na arte egípcia: as representações humanas", Cadmo, 18, Lisboa, 2008, pp. 81-105.

Luís Manuel de Araújo, "Novos objectos do núcleo egípcio da colecção Rui Assis Ferreira", Cadmo, 18, Lisboa, 2008, pp. 107-120.

\section{Cadmo 19}

André de Campos Silva, "O problema do livre arbítrio e da intervenção divina na Instrução de Ptah-hotep", Cadmo, 19, Lisboa, 2009, pp. 9-32.

Pedro de Abreu Malheiro, “A realeza egípcia do Império Antigo: perspectivas sobre a interacção do soberano com os seus dignitários", Cadmo, 19, Lisboa, 2009, pp. 33-64.

Telo Ferreira Canhão, "O grande intendente Rensi», Cadmo, 19, Lisboa, 2009, pp. 65-96.

Júlia Pereira de Almeida e Luís Manuel de Araújo, «Escaravelhos egípcios em Portugal», Cadmo, 19, Lisboa, 2009, pp. 97-130.

José das Candeias Sales, "Cinema e história antiga. A propósito do filme Cleopatra (1963), de Joseph Leo Mankiewicz - 1. ${ }^{\text {a }}$ parte”, Cadmo, 19, Lisboa, 2009, pp. 131-154.

\section{Cadmo 20}

Josep Padró, «El mal, el pecado y el castigo en el antiguo Egipto», Cadmo, 20, Lisboa, 2010, pp. 11-28. 
Telo Ferreira Canhão, "O rei Nebkauré Kheti», Cadmo, 20, Lisboa, 2010, pp. 29-50.

André de Campos Silva, "Algumas reflexões sobre os temas da origem da morte, do estatuto ontológico do defunto e da escatologia universal no capítulo 175 do Livro dos Mortos", Cadmo, 20, Lisboa, 2010, pp. 51-70.

Paulo Carreira, "Akhenaton: realidade e representações", Cadmo, 20, Lisboa, 2010, pp. 71-92. Júlia Pereira de Almeida, "O tratado entre Ramsés II e Hattusili III", Cadmo, 20, Lisboa, 2010, pp. 93-112.

Rogério Sousa, "O simbolismo dos amuletos cardiacos no antigo Egipto", Cadmo, 20, Lisboa, 2010, pp. 113-140.

Luis Manuel de Araújo, "Três pequenas colecções egípcias particulares", Cadmo, 20, Lisboa, 2010, pp. 141-148.

João Camacho, "As cidades "bíblicas" de Pi-Ramsés e Pi-Atum", Cadmo, 20, Lisboa, 2010, pp. 149-164.

J. M. Simões Ferreira, "As diversas faces da venustas, ou intencionalidade estética na arquitectura do antigo Egipto segundo o Papiro Harris I. O templo egípcio como obra de arte total", Cadmo, 20, Lisboa, 2010, pp. 165-176.

Filipe Neves do Carmo, "Relações externas do Egipto no período saíta", Cadmo, 20, Lisboa, 2010, pp. 177-194.

José das Candeias Sales, "Cinema e História Antiga. A propósito do filme Cleopatra (1963), de Joseph Leo Mankiewicz - 2. ${ }^{\text {a }}$ parte", Cadmo, 20, Lisboa, 2010, pp. 195-236.

\section{2) Civilizações da Mesopotâmia (Sumérios, Acádios, Babilónios, Assírios)}

\section{Cadmo 1}

Emanuel Bouzon, «A propriedade fundiária na Baixa Mesopotâmia durante o período paleobabilónico", Cadmo, 1, Lisboa, 1991, pp. 9-30.

António Ramos dos Santos, "Os tratados adê do reinado de Assarhadon: contexto e significado", Cadmo, 1, Lisboa, 1991, pp. 99-117.

\section{Cadmo 2}

Emanuel Bouzon, "O alcance social da șimdat šarrim nos contratos paleobabilónicos de Larsa", Cadmo, 2, Lisboa, 1992, pp. 77-100.

António Ramos dos Santos, "Fontes documentais para o estudo da Babilónia Recente", Cadmo, 2, Lisboa, 1992, pp. 117-132.

\section{Cadmo 3}

Emanuel Bouzon, "Lei, ciência e ideologia na composição dos "códigos" legais cuneiformes", Cadmo, 3, Lisboa, 1993, pp. 21-47.

António Ramos dos Santos, “O sagrado na Babilónia Antiga», Cadmo, 3, Lisboa, 1993, pp. 61-84. 


\section{NOTAS E COMENTÁRIOS}

\section{Cadmo 4/5}

Emanuel Bouzon, "O Templo, o Palácio e o pequeno produtor na Baixa Mesopotâmia présargónica", Cadmo, 4/5, Lisboa, 1994-1995, pp. 29-51.

António Ramos dos Santos, "A familia e a preservação da propriedade na Babilónia recente", Cadmo, 4/5, Lisboa, 1994-1995, pp. 53-73.

\section{Cadmo 6/7}

Emanuel Bouzon, «A saga de Gilgameš e suas fontes”, Cadmo, 6/7, Lisboa, 1996-1997, pp. 31-61.

\section{Cadmo 8/9}

António Ramos dos Santos, "A tributação fundiária e o "serviço do rei" na Babilónia Aqueménida", Cadmo, 8/9, Lisboa, 1998-1999, pp. 107-122.

\section{Cadmo 10}

António Ramos dos Santos, "Mercadores e palácio na Babilónia Recente», Cadmo, 10, Lisboa, 2000, pp. 225-241.

\section{Cadmo 11}

António Ramos dos Santos, "Operações económicas e tipologia documental no período neobabilónico", Cadmo, 11, Lisboa, 2001, pp. 65-81.

\section{Cadmo 12}

Francisco Caramelo, "A publicação dos oráculos proféticos neo-assírios no século XIX: Contributo para uma nova perspectiva do profetismo bíblico", Cadmo, 12, Lisboa, 2002, pp. 113-121.

António Ramos dos Santos, "A assiriologia no século XIX", Cadmo, 12, Lisboa, 2002, pp. 123-136.

\section{Cadmo 13}

Emanuel Bouzon, «Propriedade e economia na antiga Babilónia até ao império de Hammurabi», Cadmo, 13, Lisboa, 2003, pp. 27-53.

António Ramos dos Santos, “As associações comerciais neobabilónicas: os empreendimentosharranu de Iddin-Marduk, descendente de Nur-Sin", Cadmo, 13, Lisboa, 2003, pp. 97-112.

\section{Cadmo 14}

Emanuel Bouzon, "O aborto provocado por agressões na legislação médio-assíria e seus paralelos nas legislações do antigo Oriente", Cadmo, 14, Lisboa, 2004, pp. 31-52.

António Ramos dos Santos, "As actividades económicas das "empresas" familiares nas sociedades antigas: o caso mesopotâmico", Cadmo, 14, Lisboa, 2004, pp. 61-75.

Pedro de Abreu Malheiro, "O processo redaccional das inscrições reais assírias. Os exemplos pontuais da época de Assurbanípal”, Cadmo, 14, Lisboa, 2004, pp. 97-108. 


\section{Cadmo 15}

António Ramos dos Santos, "As actividades económicas das "empresas" familiares nas sociedades antigas: o caso mesopotâmico", Cadmo, 15, Lisboa, 2005, pp. 33-46.

\section{Cadmo 16}

Katia Maria Paim Pozzer, "O comércio de escravos no reino de Larsa. Estudo dos arquivos de Ubar-Šamaš», Cadmo, 16, Lisboa, 2006, pp. 139-156.

Marcelo Rede, «Misharum: os decretos reais e a intervenção palaciana na economia da Babilónia antiga", Cadmo, 16, Lisboa, 2006, pp. 157-200.

António Ramos dos Santos, “As actividades laborais na documentação da Babilónia Recente. Escravos, trabalhadores dependentes e livres", Cadmo, 16, Lisboa, 2006, pp. 201-218.

\section{Cadmo 17}

Célia do Carmo José, "A mulher e o casamento nas Leis de Eshnunna (LE) e no Código de Hammurabi (CH)", Cadmo, 17, Lisboa, 2007, pp. 9-26.

Maria de Lurdes Palma, "Esposas e concubinas na legislação médio-assíria», Cadmo, 17, Lisboa, 2007, pp. 27-53.

\section{Cadmo 18}

António Ramos dos Santos, "Social order in Mesopotâmia”, Cadmo, 18, Lisboa, 2008, pp. 31-40. Francisco Caramelo, «Thinking about war in ancient Mesopotamia: A prophetic discourse of legitimacy", Cadmo, 18, Lisboa, 2008, pp. 41-52.

\section{Cadmo 19}

Maria de Lurdes Palma, "Tiglat-pileser I à luz do debate sobre a nova cronologia para a história do Próximo Oriente antigo", Cadmo, 19, Lisboa, 2009, pp. 155-169.

\section{Cadmo 20}

Maria de Lurdes Palma, "Taram-kubi: uma mulher de negócios no período paleo-assírio", Cadmo, 20, Lisboa, 2010, pp. 267-294.

Manuela Bispo, «Erra/lsum. Contributo para a análise do divino na Babilónia à luz do poema de Erra", Cadmo, 20, Lisboa, 2010, pp. 295-316.

Juan Luis Montero Fenollós, «Etemenanki: a zigurate da Babilónia. Contributo para a sua reavaliação arquitectónica”, Cadmo, 20, Lisboa, 2010, pp. 317-338.

Francisco Caramelo, “A Babilónia no destino de Alexandre”, Cadmo, 20, Lisboa, 2010, pp. 339-346.

\section{3) Síria-Palestina (Hebreus, Fenícios e Cananeus)}

\section{Cadmo 1}

José Nunes Carreira, "Hermopolitan traditions in Philo Byblius' Phoenician History", Cadmo, 1, Lisboa, 1991, pp. 31-44. 
José Augusto Ramos, “Ugarit, Fenicia e Canaã: questões de metodologia e delimitação historiográfica", Cadmo, 1, Lisboa, 1991, pp. 45-63.

Francolino Gonçalves, "História antes de Heródoto: o caso de Israel», Cadmo, 1, Lisboa, 1991, pp. 65-98.

\section{Cadmo 2}

Francolino Gonçalves, "Os profetas hebraicos e a política do seu tempo: o caso de Isaías", Cadmo, 2, Lisboa, 1992, pp. 15-59.

\section{Cadmo 3}

José Nunes Carreira, "Dilúvio e destruição da humanidade. Actualidade de um antimito", Cadmo, 3, Lisboa, 1993, pp. 7-20.

\section{Cadmo 6/7}

Julio Trebolle, «Moisés y David en los libros de Samuel-Reyes», Cadmo, 6/7, Lisboa, 19961997, pp. 7-29.

José Nunes Carreira, "Conteúdos, forma e método na exegese de narrativas de criação", Cadmo, 6/7, Lisboa, 1996-1997, pp. 63-88.

Nuno Simões Rodrigues, "Saul rei: herói trágico na historiografia de Israel», Cadmo, 6/7, Lisboa, 1996-1997, pp. 89-122.

\section{Cadmo 8/9}

Francolino Gonçalves, “Isaías e Jeremias: Dois "profetas" face à política internacional de Judá”, Cadmo, 8/9, Lisboa, 1998-1999, pp. 9-28.

\section{Cadmo 10}

Francolino Gonçalves, «Exílio babilónico de "Israel”. Realidade histórica e propaganda», Cadmo, 10, Lisboa, 2000, pp. 167-196.

José Augusto Ramos, “Baal, o que é um deus?», Cadmo, 10, Lisboa, 2000, pp. 197-223.

\section{Cadmo 12}

Julio Trebolle Barrera, «Libros bíblicos y apócrifos entre los manuscritos de Qumrán», Cadmo, 12, Lisboa, 2002, pp. 137-155.

\section{Cadmo 13}

José Nunes Carreira, "A Terra Santa em relatos portugueses de viagem (séculos XVI-XVII)", Cadmo, 13, Lisboa, 2003, pp. 55-78.

\section{Cadmo 15}

Julio Trebolle, Pablo Torijano, Andrés Piques, "Características distintivas del texto masorético del libro de Reyes", Cadmo, 15, Lisboa, 2005, pp. 9-21. 


\section{Cadmo 17}

Maria Ana Valdez, «From the periods of history towards the end", Cadmo, 17, Lisboa, 2007, pp. 55-80.

\section{Cadmo 18}

Francolino J. Gonçalves, "Fundamentos da mensagem moral dos profetas bíblicos», Cadmo, 18, Lisboa, 2008, pp. 9-29.

\section{Cadmo 20}

José Augusto Ramos, "Deus em pronomes pessoais, no uso pré-clássico e bíblico", Cadmo 20, Lisboa, 2010, pp. 237-256.

Tiago de Brito Penedo, "O papel do monstro da criação na literatura veterotestamentária: uma análise comparativa", Cadmo, 20, Lisboa, 2010, pp. 257-266.

\section{4) Grécia}

\section{Cadmo 16}

Maria Manuela Alves Dias, "O que Penélope dizia quando em silêncio tecia", Cadmo, 16, Lisboa, 2006, pp. 219-225.

Maria Helena Ureña Prieto, «Breves apontamentos sobre o homossexualismo grego (de Platão à Época Helenística)", Cadmo, 16, Lisboa, 2006, pp. 227-236.

\section{Cadmo 17}

Carmen Leal Soares, «Fronteiras geo-culturais do Mundo Antigo na obra de Heródoto: Código de vida feminino versvs código de vida masculino", Cadmo, 17, Lisboa, 2007, pp. 143-158.

\section{Cadmo 18}

Maria de Fátima Silva, «Eneias, um herói da lliada», Cadmo, 18, Lisboa, 2008, pp. 121-132.

David G. Santos, «Mitologia e drama na metafísica de Plotino”, Cadmo, 18, Lisboa, 2008, pp. 133-168. Paulo Sérgio Margarido Ferreira, "Contributo para o estudo das relações entre a historiografia e a sátira menipeia”, Cadmo, 18, Lisboa, 2008, pp. 181-191.

\section{Cadmo 19}

Maria de Fátima Silva, "Heródoto e a guerra. Um desafio à sophrosyne", Cadmo, 19, Lisboa, 2009, pp. 171-179.

Luísa de Nazaré Ferreira, "L'interprétation de Simonide dans le De Herodoti Malignitate de Plutarque", Cadmo, 19, Lisboa, 2009, pp. 181-188.

\section{Cadmo 20}

Nuno Simões Rodrigues, "Ainda Clitemnestra, a "mulher de máscula vontade", Cadmo, 20, Lisboa, 2010, pp. 393-406.

Carmen Soares, "Os rivais do político verdadeiro: homens, animais e monstros. Contributos d'O Político e d'A República para o retrato dos falsos políticos", Cadmo, 20, Lisboa, 2010, pp. 407-416. 
Delfim Ferreira Leão, "Cidadania, autoctonia e posse de terra na Atenas democrática", Cadmo, 20, Lisboa, 2010, pp. 445-464.

Maria do Céu Fialho, "Estratégias discursivas em Plutarco, Vida de Fócion», Cadmo, 20, Lisboa, 2010, pp. 465-478.

\section{5) Roma}

\section{Cadmo 14}

Nuno Simões Rodrigues, "Subtilezas orientais no Satyricon de Petrónio", Cadmo, 14, Lisboa, 2004, pp. 77-95.

\section{Cadmo 16}

Armando Senra Martins, "Das XII Tábuas ao século I a. C. Esboço histórico e jurídico do casamento romano", Cadmo, 16, Lisboa, 2006, pp. 263-274.

Tatiana Kuznetsova-Resende, “Religião e viticultura na Hispânia romana”, Cadmo, 16, Lisboa, 2006, pp. 275-284.

\section{Cadmo 17}

Rodrigo Furtado, "Vinho novo em velhos odres"? Porque foi assassinado Marco Aurélio Antonino?», Cadmo, 17, Lisboa, 2007, pp. 187-228.

Cláudia Teixeira, "Os paralelos ficcionais entre a biografia de Heliogábalo na Historia Augusta e a cena "Trimalchionis" do Satyricon de Petrónio", Cadmo, 17, Lisboa, 2007, pp. 229-242.

\section{Cadmo 18}

Renata Senna Garraffoni, «História Antiga e as camadas populares: repensando o Império Romano", Cadmo, 18, Lisboa, 2008, pp. 169-180.

Rodrigo Furtado, «Em torno do principado de Severo Alexandre: a senatorialização da imagem do principe e o campo de Marte», Cadmo, 18, Lisboa, 2008, pp. 193-215.

\section{Cadmo 19}

Cláudia Afonso Teixeira, “Ficção e poder na Eneida de Virgílio”, Cadmo, 19, Lisboa, 2009, pp. 189-198. Adriaan de Man, «Funções estruturantes de algumas villae pós-romanas», Cadmo, 19, Lisboa, 2009, pp. 199-208.

\section{Cadmo 20}

Aurora Videira Mocho, "O lugar das utopias na Fedra de Séneca. Tempo mítico e espaço imaginado", Cadmo, 20, Lisboa, 2010, pp. 499-518.

Rodrigo Furtado, "Partes Agrippinae: problemas em torno de um grupo político", Cadmo, 20, Lisboa, 2010, pp. 519-542.

José Luís Lopes Brandão, "Galba e Otão: duas perspectivas biográficas", Cadmo, 20, Lisboa, 2010, pp. 543-560. 
Sérgio Lourosa Alves, "As ideias cosmopolitas de Marco Aurélio", Cadmo, 20, Lisboa, 2010, pp. 561-582.

\section{5) Misto (artigos que reúnem em si mais do que uma categoria)}

\section{Cadmo 1}

Geraldo Coelho Dias, "Os "Povos do Mar" e a "Idade Obscura" no Médio Oriente Antigo", Cadmo, 1, Lisboa, 1991, pp. 145-153.

\section{Cadmo $4 / 5$}

José Nunes Carreira, "Em busca da vida eterna: frustrações asiáticas e soluções egipcias", Cadmo, 4/5, Lisboa, 1994-1995, pp. 7-27.

Ana Maria Moreira e Nuno Simões Rodrigues, "O uso dos clássicos no Comentário de Frei Luís de Sottomaior a Cant. 4, 1a", Cadmo, 4/5, Lisboa, 1994-1995, pp. 95-120.

\section{Cadmo 8/9}

Emanuel Bouzon, «Escravidão e dividas na legislação cuneiforme e seus reflexos na legislação do antigo Israel», Cadmo, 8/9, Lisboa, 1998-1999, pp. 29-48.

\section{Cadmo 10}

Antonio Loprieno, "La menace du sacré en Egypte et en Israël», Cadmo, 10, Lisboa, 2000, pp. 123-145.

Geraldo Dias Coelho, "Penetração e presença do Egipto em Canaã (Israel-Síria)", Cadmo, 10, Lisboa, 2000, pp. 111-121.

Alberto Bernabé, "Los mitos hititas sobre Kumarbi y la Teogonía de Hesíodo: forma y diversidad de concepción religiosa", Cadmo, 10, Lisboa, 2000, pp. 147-166.

\section{Cadmo 11}

Emanuel Bouzon, "Os contratos de arrendamento de pomares no direito do Oriente Antigo", Cadmo, 11, Lisboa, 2001, pp. 33-54.

\section{Cadmo 12}

José Ribeiro Ferreira, "Relações e conflitos entre Ocidente e Próximo Oriente: O caso de Tróia", Cadmo, 12, Lisboa, 2002, pp. 41-61.

Armindo dos Santos Vaz, "A renovação dos estudos bíblicos com as literaturas do Antigo Oriente", Cadmo, 12, Lisboa, 2002, pp. 157-193.

Maria de Fátima Silva, "A visão do outro. Configuração colectiva dos Persas em Heródoto", Cadmo, 12, Lisboa, 2002, pp. 195-210.

\section{Cadmo 15}

Nuno Simões Rodrigues, «Economia e sociedade da Babilónia segundo os autores greco-latinos. I-O período clássico", Cadmo, 15, Lisboa, 2005, pp. 47-70. 
José das Candeias Sales, «Prodígios e presságios como marcas da sobrenaturalidade de um herói predestinado: o caso de Alexandre Magno», Cadmo, 15, Lisboa, 2005, pp. 71-104.

\section{Cadmo 16}

Nuno Simões Rodrigues, «Economia e sociedade da Babilónia segundo os autores greco-latinos. II - O período imperial», Cadmo, 16, Lisboa, 2006, pp. 237-262.

\section{Cadmo 17}

Nuno Simões Rodrigues, «Economia e sociedade da Babilónia segundo os autores greco-latinos. III - Conclusões", Cadmo, 17, Lisboa, 2007, pp. 159-186.

\section{Cadmo 20}

Maria de Fátima Silva, "O Nilo na literatura grega", Cadmo, 20, Lisboa, 2010, pp. 369-392.

Cristina Santos Pinheiro, “Corpos em construção: natureza e condições do corpo feminino na Antiguidade greco-romana", Cadmo, 20, Lisboa, 2010, pp. 479-498.

\section{6) Diversos (artigos sobre outros temas)}

\section{Cadmo 8/9}

José Augusto Ramos, "O tempo antes do tempo", Cadmo, 8/9, Lisboa, 1998-1999, pp. 49-68.

\section{Cadmo 10}

Mario Liverani, "The tribunal of History", Cadmo, 10, Lisboa, 2000, pp. 243-254.

\section{Cadmo 12}

José Nunes Carreira, "Século de Verdi - o despertar de um gigante», Cadmo, 12, Lisboa, 2002, pp. 9-39.

Sérgio Campos Matos, "Oriente e orientalismo em Portugal no século XIX: O caso de Oliveira Martins", Cadmo, 12, Lisboa, 2002, pp. 211-224.

Maria João Neto, «O poder das formas. Revivalismos orientais na arte portuguesa contemporânea", Cadmo, 12, Lisboa, 2002, pp. 225-241.

Rui Mário Gonçalves, «Influências orientais na transformação da linguagem pictórica ocidental», Cadmo, 12, Lisboa, 2002, pp. 243-249.

\section{Cadmo 13}

Isabel Pires de Lima, "O Oriente literário entre dois séculos", Cadmo, 13, Lisboa, 2003, pp. 129-146.

\section{Cadmo 18}

José Augusto Martins Ramos, "Metaforicidade humana do mar pré-clássico", Cadmo, 18, Lisboa, 2008, pp. 53-80. 


\section{Cadmo 19}

Rui Morais, "Um caso exemplar: Cenáculo e o coleccionismo no Portugal de Setecentos", Cadmo, 19, Lisboa, 2009, pp. 209-228.

\section{Cadmo 20}

Luísa de Nazaré Ferreira, "O sortilégio do olhar. Helena na pintura de Gustave Moreau", Cadmo, 20, Lisboa, 2010, pp. 417-430.

Nídia Catorze Santos, «Reviver as guerras medo-persas de Heródoto no romance histórico dos inícios do século XX: helenismo e cultura clássica na época vitoriana", Cadmo, 20, Lisboa, 2010, pp. 431-444.

\section{Vinte anos da revista Cadmo - um balanço}

Em 2010 a revista Cadmo completou os seus vinte anos de publicação regular, sendo esta uma data assinalável e significativa para uma revista universitária. Com efeito, poucas resistem tanto tempo, quer seja por razões financeiras ou por razões técnicas.

“Cadmo é a única publicação periódica de Orientalística antiga no espaço linguístico lusófono - continuamos a erguer a voz modesta no concerto da História Antiga portuguesa." Assim afirmava o Professor José Nunes Carreira, director da revista Cadmo há quinze anos atrás (Editorial do $n^{\circ} 4 / 5$, Lisboa, 1994-1995, p. 4). A verdade é que desde então a revista continuou a sua publicação regular e meritória, sendo pioneira no seu objecto de estudo e na sua capacidade interdisciplinar.

Reunindo o esforço de investigadores portugueses e estrangeiros, cada publicação anual apresenta um conjunto de estudos nas áreas do Egipto Faraónico, Civilizações da Mesopotâmia, Síria-Palestina, Grécia e Roma, entre outras. Além disso, contém outros úteis capítulos, como, por exemplo, o das Recensões que, além de fornecer pistas de leitura ao leitor, orienta-o para livros cientificamente sérios.

Decorridos vinte anos frutuosos, esperamos que a Cadmo continue a viajar do Oriente ao Ocidente, pelo Egipto majestoso e duradouro, pelos pólos de irradiação civilizacional da Mesopotâmia, pela amálgama de povos e culturas da Síria-Palestina, pela clarividente e reflexiva Grécia, não esquecendo a pragmática e outrora grandiosa Roma. Que sempre, de forma científica, continue a revelar a história destes povos, dos quais somos herdeiros. 
Grandes áreas de investigação da revista:

dados estatísticos por número de artigos

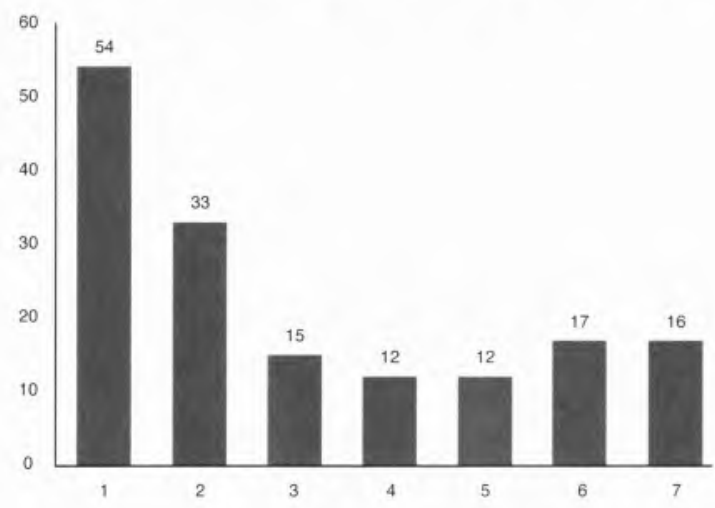

1 - Egipto Faraónico

2 - Civilizações da Mesopotâmia (Sumérios, Acádios, Babilónios e Assírios)

3 - Síria-Palestina (Hebreus, Fenícios e Canaã)

4 - Grécia

5 - Roma

6 - Misto (artigos que reúnem em si mais do que uma categoria)

7 - Diversos (artigos sobre outros temas)

\section{Grandes áreas de investigação da revista:} dados estatisticos em percentagem

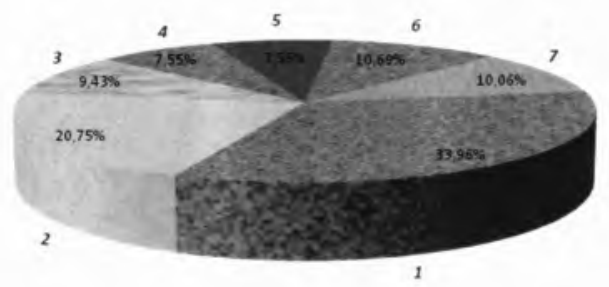

1 - Egipto Faraónico

2 - Civilizações da Mesopotâmia (Sumérios, Acádios, Babilónios e Assírios)

3 - Síria-Palestina (Hebreus, Fenícios e Canaã)

4 - Grécia

5 - Roma

6 - Misto (artigos que reúnem em si mais do que uma categoria)

7 - Diversos (artigos sobre outros temas) 